\title{
Indian Translation Traditions: Perspectives from Sujit Mukherjee
}

ANJALI CHAUBEY

\section{Abstract}

This paper revisits Sujit Mukherjee's seminal work Translation as Discovery and Other Essays on Indian Literature in English Translation (1981) to analyze his contribution in foregrounding the translation traditions of India. In the book, he uses the term 'transcreation' to refer to translation as a practice in the Indian literary scenario and cites examples from the ancient to modern times, to show how we have perceived and practiced translation. He centers this process in contrast to the western practice of the same, which makes translation a postcolonial exercise. He emphasizes the need to focus on the pragmatic analysis of the process of translation and looking at the 'Indo-English literature', as 'a limb of the body, the purusha, that is Indian literature' which would help in decolonizing literary studies.

Keywords: Sujit Mukherjee, Translation, Transcreation, India, Indo-English, Postcolonial, Literary Studies.

As latter-day Calibans we were taught English and our profit on it has been that we learned how to translate into English. Out of such remembering and recording will come India's theories of translation especially of translating into English (Mukherjee 2004: 37).

It is soon going to be forty years since the first publication of the book Translation as Discovery. One keeps coming back to Sujit Mukherjee as a guiding star when one seeks to understand various entry points in the area of translation studies in the Indian context. His words have been prescient in wresting translation as an effective tool of decolonization of literary studies as well as connecting Indian languages with 
each other. In his exemplary career, Muherjee has looked at various contours of Indian Literary traditions but his interest in translation supersedes everything else. In his doctoral thesis titled, "A passage to America: Reception of Tagore in the United States", he has looked at how Tagore is received in English translation. The book under discussion is a collection of his intellectual ponderings of over a decade. The importance of this volume can be gauged from the limited amount of Indian archives (in English) on this field till date: R. S. Gupta's Literary Translation (1999), Tejaswini Niranjan's Siting Translation: History, Post-Structuralism, and the Colonial Context (1992), Susan Bassnett and Harish Trivedi's Post Colonial Translation: Theory and Practice (1999), Sujit Mukherjee's Translation as Recovery (2003), Rita Kothari's Translating India: The Cultural Politics of English and Decentering Translation (2009) and GJV Prasad's India in Translation, Translation in India (2019). But Mukherjee in a way has paved the way for others to trudge over as this was one of the first books to look at the changing translation practices in India from the precolonial to postcolonial times.

Significance of Translation as Discovery: The two seminal texts by Mukherjee cover a gap of two decades, complementing and completing the intellectual journey of the author in this area. Yet, Discovery holds a lot of more merit than its sequel, for it was an epoch-making text of the time where somebody gave such a sustained analysis of IndoEnglish writing (a term he uses to refer to Indian literature in English translation, after Gokak), discussing the ethics and ideals of translation, assessing its existing scene and analyzing the possibility of extending its territory in a meaningful way etc. Mukherjee says that the theories dealing with the cultural aspects of translation are helpful in as far as, they lay out the politics involved in the process, the role of the translator, and in developing insights into the ways in which this activity has 
been put to use over the ages and across continents. However, he says these theories do not help in the actual process of translation. In the 'Preface' to the edition of this volume, he says: "No attempt has been made here to propound any theory of translation; this may be left to those who do not actually translate" (ix), which goes on to indicate that such theories are of not much avail when it comes to practice. Translation is a practical exercise; every time a translator sets down to a text $\mathrm{s} /$ he has to negotiate her/his own terms and priorities to render the text into another language. Taking the stand that no general theorization is possible on this aspect, he focuses on the pragmatic analysis. In this volume, he has also attempted to carve a niche for 'Indo-English literature', which in his words is 'a limb of the body, the purusha that is Indian literature'. In doing so, he has successfully attempted to define the boundaries of Indo-English Writing and has been able to trace briefly the translation practice in the Indian literary scene from the ancient to the modern times showing how the way we have perceived and practiced translation (as transcreation) is different from the western practice of the same. He analyses the beginning of the trend of translation into English from Indian languages and underlines the need for promoting it in the post-colonial times:

Underlying this recommendation is the belief that we cannot do without the English language in the foreseeable future. If this prospect is accepted, then we must ensure that the labor of learning English is fully exploited in the development of our literary culture. The proverbial brace of birds can be killed by the same stone if we direct the learning of English towards the discovery not of England's literature but of the literature written in the many Indian languages (Mukherjee 1981: 38). 
Clearly, Discovery attempts to give a push to the learning and 'discovery' of Indian literature through promoting translations. This is a way of dealing with post-coloniality without being rueful of the encounter that had taken place in the past. It is a part of the ideological stand of critics and theorists who look at post-colonialism as an 'emancipatory concept' that aims at looking at 'the continuities and ruptures in the (native) civilization'. Paranjape in 'Coping with Post-colonialism' says:

Postcolonialism like most things of western origin can neither be rejected nor accepted fully. We have each to work out our own adjustment and compromise with it. We may try to use it against the grain, subvert it to our advantage, or deploy it to our own benefit all the while endeavoring to safeguard ourselves from the distorting tendencies (Trivedi \& Mukherjee 84: 1996).

Despite using the language, which is a part of the colonial legacy, the efforts are in the direction of developing and encouraging the native culture through translation. India's multilingualism comes in the way of establishing a common platform where different bhasha writers can interact with each other, which prohibits them from looking at the sameness or the differences of each other. This interaction and communication are very essential in the development of a healthy literary tradition and criticism, to which Mukherjee refers to in Recovery. However, he realizes that translation into English may inhibit the growth of other translations (into Indian languages) and the language may not be the best language to translate Indian literature: "The discovery that awaits to be made - and will be easier to make when every Indian language has acquired in translation, a large enough number of literary texts from all the other Indian languages - is that there may be like Indian music or painting or sculpture an Indian literature after all" (viii). But the fact remains that the 
English language is indispensable in modern times and through Indo-English Writing an Indian would:

...be in a position to reach beyond his region to a larger world. Since he has to learn English anyway, he will use this training primarily for learning more about his country's literature; secondarily, he is enabled to reach farther out beyond the borders of his country. IndoEnglish literature is therefore the most practical link literature of today's India (Mukherjee 1981: 39).

Mukherjee's methodology is geared toward creating a niche for Indo-English Writing as distinct from Indian Writing in English, as part of Indian literature. He emphasizes the need to develop native translation culture, which would give a push to the growth of Indian literature through English translation. In Discovery, he holds the steadfast view that the English language has the possibility of creating link literature for India, which is otherwise not possible in our multilingual culture. This proposal is based on his assumption that the English language is the common possession of all Indians. Even if he is referring to educated Indians who are engaged in reading and writing literature, still one has certain reservations in accepting his assumption. Back in the 1980s there was a considerably limited number of elite Indians who had the privilege of being educated in the English language. The sizeable amount coming out of government school education was not in the position of appreciating literature in English (translation or otherwise), for the compulsory English paper did not equip them sufficiently. But this assumption is valid in today's time when the equations have reversed and English medium instruction has become the norm even in many government schools (which are only being joined by the lesser privileged, even a lower-middle-class Indian strives hard to carry on the education of her/his child enrolled in public schools). 
Notwithstanding the enriching aspect of translation, it is worth analyzing the need for link literature for India. The multilingualism of India is not a new phenomenon; we were comfortable with it for a long till the advent of English (people and the language) and their departure (only the people, the language was here to stay). The anxiety was to reunite the fragmented Bharat (in this case by translating it as India). But there never was a united Bharat and we never felt the need for it. However, postcolonialism entails unification and solidarity. Of the many accusations an Indian writer in English is charged with is that it is "babu fictions" (to borrow the title of a Tabish Khair's insightful text), that $\mathrm{s} /$ he does not share the issues and concerns of bhasha writers. Thus, translations from regional literature into English would at least help remove this charge and bring writers together. The writer is defending the stance of the translators who are engaged in English translations, by virtue of being more at home in this language than any other regional language. The project of the writer is to channel this command over the language in translating from bhashas and not merely from European and American texts. In the journey between the two texts, the author also analyzes the changing contours of Indian translation practice:

Quite significantly, we do not have a word in any Indian language that would be the equivalent of the term 'translation'... (which) suggests that the concept itself was not familiar to us. Instead, when we admired a literary text in one language, we used it as a take-off point and composed a similar text in another language (Mukherjee 2004: 45).

What happens when two opposing practices of translation i.e., Indian tradition of looking at the original as merely the starting point and the western practice of utter fidelity to the original, confluence? And besides this juggling, Indian translating into 
English adds another twist to the western 'translation' practice: that the language of the translation is no longer the first language of the translator. As a result of this peculiar phenomenon, he says that good translations continue to be rare, passable translations are our usual fare while bad translations proliferate. The author indicates at the sordid state not to discourage translations but to highlight the need for setting and pursuing standards of translation, which is another important project of this book. At length, he deals with questions such as who should translate, how he should go about it, who is the proper judge/reviewer of translation: one who can read the original and the translation both or one who does not know the language of the original text, etc. Thus, an ideal translator for Mukherjee is one who is proficient in both the languages (the source and the target languages), should be a practiced reader and meaning maker (teacher, editor, or critic) of literature, and must habitually write in English. Therefore, not anybody can and should bake her/his cake in the name of rendering a piece of literature into another language. The task requires consistent and honest efforts along with talent and a knack for translation. He sees that the problem with Indo-English Writing is that it has been carried on in an unplanned manner; there is no mechanism to ensure the quality of translations and also what gets translated. It is the writers and literati who have defined the contours and set the standards of Indian English Writing, likewise for Indo-English Writing to carve a niche of its own the onus again lies on those who are engaged with the language or as Mukherjee puts it, who earn their living through the language i.e., scholars, critics, teachers and students of English language. In no uncertain terms the author is encouraging and promoting the Indo-English practitioner to come up with more and more quality translations. Even the second edition of Discovery which came out in 1990 did not show any shift in the writer's 
ideology. Significantly, the author does not offer the same support to this project in Recovery, with which I would deal in the subsequent portion.

In Discovery he has attempted to remove some of the prejudices associated with translated texts and wants to assign the translator a rightful place in the literary scene. S/he should not be placed next to the thief and the seller, "the thief, the translator, and the seller were necessary for nineteenth-century European colonial enterprise" (125). At the same time, he also reminds the translator of the responsibility s/he carries when $\mathrm{s}$ /he undertakes work for translation, "not anything can be swaddled to the unsuspecting readers. Underlining the importance of ethics in translation, he discusses at length how a text can be approached, depending upon the level of interpretation and dedication of the translator. Citing the translations of similar passages from Bibhutibhusan Bandopadhya's Pather Panchali (1922) from three different translators, he instructs the aspiring translator about the intricacies of the field: sustained in-depth understanding and interpretation of the original. The author does not give ideal theorizations, rather he hints subtly at the disappointing renderings of several texts. His usage of secondary sources is remarkable in the sense that it forwards his arguments and brings his point home effortlessly. He practically tries to cover all the aspects of this field. From the way courses can be designed on Indo-English Writing, the method and criteria of selection of texts: author-specific study or period-specific (ancient, medieval, and modern texts), theme-specific (for example literature on nationalist movement, partition, women's issues, etc.) or simply by genre.

In some ways, Mukherjee's efforts in Discovery are directed at validating the field of Indo-English Writing, which would include translations into English during his time. Although 
Indian Translation Traditions: Perspectives from Sujit Mukherjee

translations into English were proliferating in the 1970s and 80s and this body had grown substantially, it was not getting its due attention among theoretical discourses. Mukhherjee has drawn attention toward this 'limb' of Indian literaturedescribing its significance and its various aspects: '...odd things did happen in the colonial period which must be affecting our postcolonial outlook on translation without our realizing it, and this needs to be studied' (Mukherjee 2004: 36).

Mukherjee is his own critic in Translation as Recovery where he revisits his own formulation after two decades. He is disappointed that 'translation' invariably means, into English. Translations into English have clearly overtaken and affected translations between bhashas. In Recovery the author is no longer as enthusiastic about this project as he was in Discovery. For how long should bhasha literature be read only in English translations? If reading and studying literature help in the development and growth of that language, it must be read in the language of its composition. English being a global language, Indo-English literature would always find a readership, within the continent and beyond. In order to develop the native literary sensibility, a room must be created for bhasha language and its literature, mere incorporation of a few texts into the syllabi of English literature would not suffice. He does carry on his project of setting standards of translational practice and ethics but no longer promotes and encourages translations into English with the same vigor. One wonders what the title essay 'translation as recovery' would have been on. Perhaps the need to 'recover' the Indo-English texts in bhasha languages might have been a part of this essay if had lived to complete the book. Thus, translations into English can merely be a part of the larger project of creating and developing a native tradition of translation and the need of the time is to give a push to the practice of translations among bhasha literature. 
Anjali Chaubey

\section{References}

Bassnett, Susan \& Harish Trivedi. 1998. Post-Colonial

Translation: Theory and Practice. London: Routledge.

BANDYOPADHYAY, BiBHUTI BHUShan. 1922. Pather Panchali.

Calcutta: Writers Workshop.

GuPTA, R. S. Literary Translation. 1999. New Delhi: Creative Books.

KHAIR, TABISH. 2001. Babu Fictions: Alienation in Contemporary Indian Novels. New Delhi: Oxford UP.

KothaRI, RITA. 2003. Translating India: The Cultural Politics of English. Revised 2006. New Delhi: Foundation Books.

MuKHERJEe, SuJIT. 1981. Translation as Discovery and Other Essays on Indian Literature in English Translation. New Delhi: Allied Publishers.

MukHERJEe, SuJiT \& MEenAKShi MukHeRJee. 2004. Translation as Recovery. New Delhi: Pencraft International. NiRANJAN, TEJaswINI. 1992. Siting Translation: History, PostStructuralism, and the Colonial Context. California: University of California Press.

PARANJAPE, MAKARAND. 1996. Coping with Post-Colonialism.

In Harish Trivedi \& Meenakshi Mukherjee (eds.), PostColonialism: Theory, Text and Context. Shimla: Institute of Advanced Studies.

***

\section{Cite This Work:}

Chaubey, Anjali. 2021. Indian Translation Traditions: Perspectives from Sujit Mukherjee. Translation Today, Vol. 15(1). 181-190. DOI:10.46623/tt/2021.15.1.no2 